Opinion

\title{
Role of Science, Technology and Innovation in Ensuring Sustainable Inclusive Development*
}

\author{
R GADAGKAR ${ }^{\#}$ \\ Centre for Ecological Sciences and Centre for Contemporary Studies, Indian Institute of Science, Bangalore \\ 560 012, India and President, Indian National Science Academy, New Delhi 110 002, India
}

(Received on 11 February 2014; Accepted on 11 February 2014)

I must confess that I am no expert to speak on the role of science, technology and innovation in ensuring sustainable inclusive development. But I wonder who is the appropriate expert? I do not believe that we have produced a significant, coherent body of knowledge that we can draw upon to ensure sustainable inclusive development. Although our broad goals may be clear, we are certainly groping in the dark for ideas on how to achieve the goal of sustainable inclusive development. Until we create such a coherent body of knowledge, we have to draw upon many different disciplines, however disjointed they may be, to make some headway. But, what disciplines can help us? Clearly there are many engineering, agriculture, medicine, demography, epidemiology, ecology, biotechnology, information technology are the obvious ones. Perhaps we may persuade people to agree to include sociology and political science. I would argue however that this list is entirely inadequate and may actually lead us in quite the wrong direction. We need to add a very different set of disciplines to our cocktail anthropology, history, archaeology, palaeontology and evolutionary biology.

There is a very good reason why we need these additional disciplines, even though we often deride them as "soft" science, if science at all. It is widely assumed that the problem of unsustainable, non- inclusive development is a recent aberration and that all was well in the past - if only we could find a way of going back to the glorious past, all would be well. It is widely believed that primitive peoples, preindustrialized peoples and pre-agricultural peoples were very unlike us, that they lived in harmony with their environment and did not commit organized genocide. Recent research in anthropology, history, archaeology, palaeontology and evolutionary biology, the very disciplines that I am pleading for, suggest that these widely held beliefs might be entirely wrong.

The ecological historian Jared Diamond (1991), in his book "The Third Chimpanzee", has put together a great deal of evidence from these disciplines to make the argument that pre-historic peoples including stone age peoples and hunter gatherers, have been causing wide-spread destruction of their environments and exterminating animal and plant species, and each other, for tens of thousands of years. Perhaps the best documented examples are the large-scale extermination of mammalian and avian mega fauna and extensive deforestation by Polynesian peoples in New Zealand and Hawai, the Malagasy people in Madagascar and American Indians in the Americas. Ironically, the best-known exterminations of "primitive" peoples by "modern" peoples come from events following the arrival of Europeans to these very regions. The shocking picture that is

\footnotetext{
*Based on a talk given during the Panel Discussion on "Role of Science, Technology and Innovation in Ensuring Sustainable Inclusive Development", held during the $101^{\text {st }}$ Session of Indian Science Congress Association, Jammu on $03^{\text {rd }}$ February 2014.

"For Correspondence: E-mail: ragh@ces.iisc.ernet.in; Tel: 91-80-23601429
} 
beginning to emerge from the disciplines of history, anthropology, archaeology, palaeontology and evolutionary biology, is that in the history of our species, there never really was a glorious past of environmentalism and blissful coexistence with nature or among different peoples.

Destruction of the environment and extermination of each other may well be the hallmark of our species. The only real difference seems to be that today we have much fewer resources per human being and a much greater potential for destroying the environment and of each other, compared to any other period in our history. Perhaps we got away with our tendency to destroy our environment and each other in the past because we had much more abundant resources and a much feebler ability for destruction. Today, our high population densities made possible by modern medicine and high destructive abilities made possible by modern technology mean that we can no longer afford to continue with business as usual. If these relatively new views are correct, then what we need are not ways of going back to the supposedly blissful past but instead to find new means and new rationale for mending our ways of the past and realizing that ways of the past are no longer possible without causing an environmental and social holocaust.

I admit that this view is not without controversy and contention. But how can we resolve the controversy and come to the correct conclusion? We need a much greater emphasis on the so called soft disciplines of history, anthropology, archaeology, palaeontology and evolutionary biology. We pay very little attention to these disciplines. Indeed we often proactively discourage these disciplines and fail to support them and their practitioners with the prestige and funding they deserve. So I will argue that scientists should first become inclusive and embrace all disciplines, hard and soft. We must develop these newer disciplines to the point where we can integrate them with the traditional branches of "hard" science and reach a point where we can have more informed consensus about the causes and consequences of human behaviour, both toward our environment and toward each other. A major advantage that we have over primitive peoples is that we have the capacity, if only we have the will, to study the history of our species and learn from history. Then primary role of science, technology and innovation in ensuring sustainable inclusive development should be to understand why we often tend to promote unsustainable and non-inclusive development. It is only then that we can hope to reverse this trend. Traditional hard sciences may give us the means to bring about sustainable inclusive development but they will not show us how to use these means and how to avoid falling back into old traps. We scientists need to become broad minded and progress beyond fighting disciplinary turf wars and one-upmanship if we wish to be able to use science, technology and innovation to ensure sustainable inclusive development.

We cannot ensure sustainable inclusive development merely by producing genetically modified crops and enacting a reservation policy. Necessary as these measures may be, they are woefully inadequate. We need to study and understand the past. When and where did civilizations in the past flourish and when did they collapse and why? When did large-scale extinctions of animal and plant species take place in the past and why? When did biodiversity-rich forests get converted into biodiversity-poor grasslands and why? It is only by analysing the past can we hope to chart a future that we desire. To analyse the past we need history for the recorded past and archaeology and palaeontology for the pre-historic period. We need anthropology to understand how different human societies behave and why? We need evolutionary biology to understand the possible animal precursors of our current behaviours. We know that behaviour is produced as a result of interaction between genes and environment (Gadagkar, 1997). We need to understand what behaviours come to us easily, almost by instinct, and what behaviours need hard work and will-power to pull off. We need to know how genes and environment interact and what combination of genes and environment produce what kind of behaviour. Only then can we fashion our environment to produce the desired behaviour. 
Where are these disciplines? Do we teach them adequately in our schools and colleges? Do we have them well represented in our universities and research institutes? Do we recognize these disciplines in our academies and other prestige giving bodies? These must be our food for thought. Only if we nurture, encourage and utilize these disciplines and create that coherent body of knowledge that I referred to in the beginning, can we hope that science, technology and innovation can play a meaningful role in promoting sustainable inclusive development.

\section{References}

Diamond J M (1991) The Rise and Fall of the Third Chimpanzee. London: Vintage Books

Gadagkar R (1997) Survival Strategies - Cooperation and Conflict in Animal Societies. Cambridge, Massachusetts, USA and

Hyderabad, India: Harvard University Press and Universities Press. 